\title{
Industry 4.0 and Decision Making
}

\author{
Frédéric Rosin ${ }^{1(凶)}$, Pascal Forget ${ }^{2}$, Samir Lamouri $^{3}$, and Robert Pellerin ${ }^{4}$ \\ 1 LAMIH UMR CNRS 8201, Arts et Métiers, Aix-en-Provence, France \\ frederic.rosin@ensam.eu \\ 2 Department of Industrial Engineering, \\ Université du Québec à Trois-Rivières, Trois-Rivières, Canada \\ ${ }^{3}$ LAMIH UMR CNRS 8201, Arts et Métiers, Paris, France \\ 4 Department of Mathematics and Industrial Engineering, École Polytechnique de Montréal, \\ Montreal, Canada
}

\begin{abstract}
Industry 4.0 is an ubiquitous term that suggests significant impacts on the productivity and flexibility of production systems. But to what extent do the various technologies associated with Industry 4.0 contribute to enhance autonomy of operational teams by helping them make better and faster decisions, particularly in the context of Lean production system? This paper proposes a model of different types of autonomy in the decision-making process, depending on whether or not the steps in the decision-making process are enhanced by technologies. This model will be tested afterwards in a use case implemented in a learning factory offering Lean management training before being tested in a real production unit.
\end{abstract}

Keywords: Industry 4.0 - Decision-making · Decision types · Autonomous production system

\section{Introduction}

Recent years have been marked by a growing interest in Industry 4.0 and related technologies by manufacturing companies of all sizes. This major technological shift has been proposed to manufacturing companies under various names: L'Industrie du futur in France, Smart Industry in the United States, Industrie 4.0 in Germany, Made in China 2025 in China, etc. In all cases, greater agility and profitability could be achieved through the inter-connectivity of products, machines, supply chains and customers, and the growing decision-making capabilities of systems [1-3].

As there are multiple definitions of the concept of Industry 4.0, the associated technologies have not been definitively identified. The Boston Consulting Group [4] proposes grouping them around nine pillars of Industry 4.0, i.e., autonomous robots, simulation, horizontal and vertical integration of systems, the Internet of Things, cyber security, cloud, additive manufacturing, augmented reality and big data analysis. Other authors have presented different lists of technologies, including Moeuf et al. [3], CEFRIO [5], Dombrowski et al. [6], Mayr et al. [7], Sanders et al. [8], and Wagner [9]. 
However, companies are struggling to define the new forms of work organization that will enable them to make the most of this technological shift. In particular, how can they take advantage of these technologies to improve decision-making and to increase the degree of autonomy of operators and machines at the operational level?

Highlighting the difficulty of industrial companies in establishing a strategic roadmap in the jungle of different terminologies, ideas and concepts, Osterrieder et al. [10] proposed a research model about the smart factory, structured around eight distinct thematic perspectives, including decision-making. They underlined the crosscutting nature of the decision-making problems that also appear in the other thematics and affect an extremely wide range of activities in manufacturing. Indeed, the use of Industry 4.0 technologies such as the Internet of Things, cobotics, augmented reality, massive data analysis, machine learning and Artificial Intelligence, can increase the autonomy of production systems, including operators and production equipment, by supporting problemsolving and other decision-making processes. This plays a central role in the concept of autonomous intelligent factories and it is not surprising to note a number of research studies focuse on data-based decision-making in production over a very broad scope covering design, scheduling, planning and process control [10]. But the proposed models do not put into perspective the different types of autonomy in the decision-making process made possible by the use of all the technologies associated with Industry 4.0.

Fortunately, decision-making models have been proposed in other contexts. Simon [11] was one of the first to propose a decision-making model, which is the most concise, yet comprehensive, characterization of a rational decision-making approach [12]. Using the ideas from Simon's model and analysing 25 decisions from different companies, Mintzberg [13] proposed a model for strategic decision-making in companies. This model is non-sequential and allows for the possibility of bypassing certain routines and interrupting the process or providing feedback.

In a similar approach, the Naturalistic Decision Making (NDM) stream [14] has worked on describing the actual decision-making process in an operational context. In this context, some authors have focused on the biases and limitations in human decisionmaking in situations with strong temporal constraints [15] or crises [14].

In the literature related to the development of artificial intelligence and intelligent agents, other ideal decision-making models have been proposed and are inspired by human decision-making models. This is notably the case of the BDI (Beliefs-DesireIntention) models [16], which aim to design artificial decision-making systems. However, no model has been proposed yet to analyse or evaluate the impact of Industry 4.0 technologies on decision-making processes.

Recognizing the potential benefits of Industry 4.0 technologies on operational decision-making, this paper proposes a generic model covering several types of autonomies that can be adopted by management, depending on the decision-making process steps that they want to reinforce in the use of technologies. The proposed decision-making process and the different types of autonomies that can be achieved are presented in Sect. 2. Section 3 discusses future research prospects and concludes this article. 


\section{Decision Making Model}

Based on the Mintzberg model [13], an ideal decision-making process is proposed (Fig. 1). It is adapted to a decision-making process that is required by the detection of a problem in the broad sense (problem or opportunity) in an operational-level manufacturing production context.

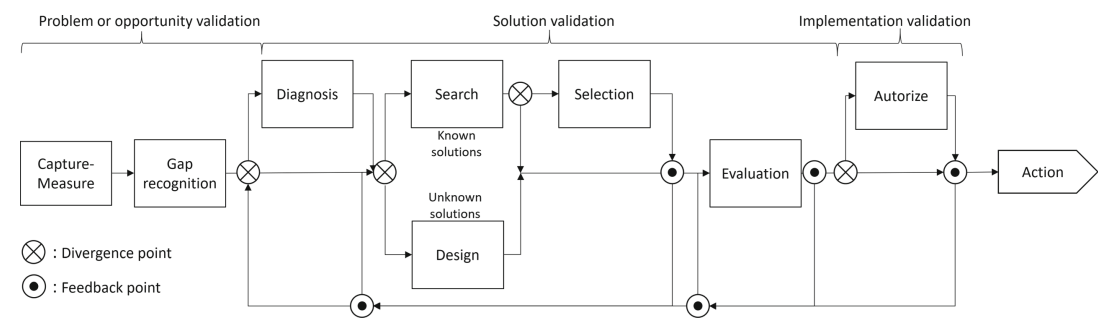

Fig. 1. Decision making process in an operational context.

This process includes three phases, similar to Mintzberg [13]: Problem or opportunity validation, Solution validation and Implementation validation. The Problem or opportunity validation phase includes the Capture-Measure and Gap recognition steps. The Capture-Measure step consists of collecting information in real time in the production system. The recognition of an abnormal situation (a problem), i.e. a discrepancy between the current situation and the desired situation, takes place in the Gap recognition stage. The Solution Validation phase includes the Diagnosis, Search, Selection or Design steps. The Diagnosis step corresponds to the analysis of the cause and effect relations in the studied situation. Depending on whether or not solutions are known to address the identified problem, the next step is to choose between the Search or Design steps. If solutions are known, the Search step allows one to look for a set of possible solutions by drawing upon the organization's memory. The Selection step is then used if the number of known solutions is too high, in order to eliminate a certain number of them and thereby lighten the work to be carried out in the Evaluation step. If no solution is known, the Design step aims to design a new solution for the problem or to modify a known solution. The Evaluation step ensures that the solution chosen will solve the situation, while respecting the constraints of the environment. The third phase includes a single step, Authorize. Here, if necessary, an authorization is issued by a higher hierarchical entity, such as a team leader, a manager or a centralized IT system. This step can be bypassed if the work center itself (an operator or a machine) has the authority to validate the implementation.

This decision-making process model can then be used to define different types of autonomy and uses of Industry 4.0 technologies. Such technologies can help a work centre, which include operators and/or machines, to enhance one or more steps in the decision-making process. 
Inspired by the four capability areas of Porter and Heppelmann's smart products [2], we propose six types of autonomy in the decision-making process based on Industry 4.0 technologies for manufacturing systems: 1) Cyber Monitoring, 2) Cyber Search, 3) Cyber Control, 4) Cyber Design, 5) Decision Support and 6) Cyber Autonomy (Fig. 2).

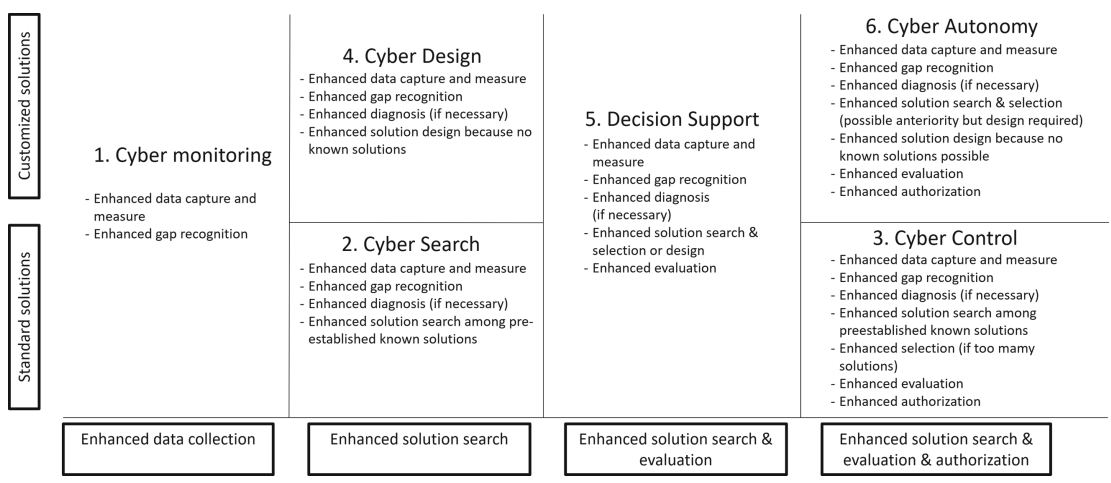

Fig. 2. Model of types of autonomy: an Industry 4.0 decision-making support model.

These six types of autonomy are not incremental, in the sense that they are not mutually inclusive and do not present a gradation in terms of intelligence or autonomy. Rather, they respond to different needs for decision support, depending on whether or not one is aware of a more or less limited set of possible solutions and the specific steps reinforced or supported by the types of Technology 4.0 involved. The Cyber Monitoring type corresponds to the reinforcement of the Capture and Measure and Gap recognition steps facilitating the collection of production data and the analysis of this data to enable the detection of an abnormal situation or an opportunity for improvement. The other stages of the decision-making process are then carried out by men according to usual practices.

The Cyber Search type corresponds to the reinforcement of the Capture and Measure and Gap recognition steps by using 4.0 technologies but adding optional support for the Diagnostic step to facilitate the identification and analysis of the reasons that underly the observed gap. The Search step is also strengthened to find possible solutions that may be applied from a set of known solutions.

The Cyber Control type is an extension of the Cyber Search type, where the final stages of the decision-making process are also assisted, including the final stage of authorizing the action. The Selection stage is reinforced if the number of possible solutions is too large. The Evaluation and Authorize steps are also reinforced; a human can then be assisted in all of the steps mobilized in this case.

The Cyber Design type is similar to the Cyber Search type but corresponds to a case in which no possible solution is known for the situation. It is the Design stage that is reinforced. In this case, the preferred 4.0 technologies must be able to assist in the design of a new solution to reduce the observed gap. 
The Decision Support type is similar to the Cyber Design type, with the addition of the reinforcement of the Evaluation step. Only the Authorization step remains entirely performed by a human without any assistance.

Finally, the Cyber Autonomy type is based on the Decision Support type, with a reinforcement in the Authorize step. As for the Cyber Control type, the human is likely to be assisted in all of the stages of the decision process mobilized in this case.

\section{Conclusion}

In this article, we have proposed an operational decision-making process model describing several types of autonomy that can be achieved with the adoption of Industry 4.0 technologies. This model is a part of a more global study aiming at studying the integration of Industry 4.0 technologies in Lean production systems.

In this regard, a previous study investigating the links between Industry 4.0 and Lean approaches showed that some Lean principles currently appear to be little or not at all improved by Industry 4.0 technologies. These include principles related to employees and teamwork, continuous improvement, stable and standardized processes, and the Toyota philosophy [17].

In order to test the proposed model of different types of autonomy in the decisionmaking process, a use case is being formalized. It is based on a learning factory and existing Lean management training modules designed in partnership with several manufacturers. A panel of Industry 4.0 technologies such as IoT, cloud, big data analysis, machine learning, simulation, augmented reality and data vizualisation will be progressively deployed. Within this framework, the different types of enhancement of the autonomy of operational teams in decision-making will be tested in order to manage in real time the production problems encountered. This will constitute a first step in validating our model before attempting its implementation within a real production unit.

\section{References}

1. Buer, S.V., Strandhagen, J.O., Chan, F.T.: The link between Industry 4.0 and lean manufacturing: mapping current research and establishing a research agenda. Int. J. Prod. Res. 56(8), 2924-2940 (2018)

2. Porter, M.E., Heppelmann, J.E.: How smart, connected products are transforming companies. Harv. Bus. Rev. 93(10), 96-114 (2015)

3. Moeuf, A., Pellerin, R., Lamouri, S., Tamayo-Giraldo, S., Barbaray, R.: The industrial management of SMEs in the era of Industry 4.0. Int. J. Prod. Res. 56(3), 1118-1136 (2018)

4. Rüßmann, M., Lorenz, M., Gerbert, P., Waldner, M., Justus, J., Engel, P., Harnisch, M.: Industry 4.0: the future of productivity and growth in manufacturing industries 9(1), 54-89. Boston Consulting Group (2015)

5. CEFRIO: Prendre part à la révolution manufacturière? Du rattrapage technologique à l'Industrie 4.0 chez les PME. Centre francophone d'informatisation des organisations (2016)

6. Dombrowski, U., Richter, T., Krenkel, P.: Inter-dependencies of Industrie 4.0 \& lean production systems - a use cases analysis. In: 27th International Conference on Flexible Automation and Intelligent Manufacturing, FAIM 2017 (2017). Procedia Manuf. 11, 1061-1068 (2017) 
7. Mayr, A., Weigelt, M., Kühl, A., Grimm, S., Erll, A., Potzel, M., Franke, J.: Lean 4.0-a conceptual conjunction of lean management and Industry 4.0. Procedia CIRP 72, 622-628 (2018)

8. Sanders, A., Elangeswaran, C., Wulfsberg, J.P.: Industry 4.0 implies lean manufacturing: research activities in Industry 4.0 function as enablers for lean manufacturing. J. Ind. Eng. Manag. 9(3), 811-833 (2016)

9. Wagner, T., Herrmann, C., Thiede, S.: Industry 4.0 impacts on lean production systems. Procedia CIRP 63, 125-131 (2017)

10. Osterrieder, P., Budde, L., Friedli, T.: The smart factory as a key construct of Industry 4.0: a systematic literature review. Int. J. Prod. Econ. 221, 107476 (2019)

11. Simon, H.A.: The new science of management decision (1960)

12. Lin, H.W., Nagalingam, S.V., Kuik, S.S., Murata, T.: Design of a global decision support system for a manufacturing SME: towards participating in collaborative manufacturing. Int. J. Prod. Econ. 136(1), 1-12 (2012)

13. Mintzberg, H., Raisinghani, D., Theoret, A.: The structure of 'unstructured' decision processes. Adm. Sci. Q. 21(2) (1976)

14. Klein, G.: Naturalistic decision-making. Hum. Factors 50(3), 456-460 (2008)

15. Power, D.J., Cyphert, D., Roth, R.M.: Analytics, bias, and evidence: the quest for rational decision-making. J. Decis. Syst. 28(2), 120-137 (2019). Special issue on cognitive bias

16. Rao, A.S., Georgeff, M.P.: BDI agents: from theory to practice. In: Proceedings of the 1st International Conference on Multi-Agent Systems, ICMAS-1995, SanFrancisco, USA, June 1995, vol. 95, pp. 312-319 (1995)

17. Rosin, F., Forget, P., Lamouri, S., Pellerin, R.: Impacts of Industry 4.0 technologies on Lean principles. Int. J. Prod. Res. 58(6), 1644-1661 (2020)

Open Access This chapter is licensed under the terms of the Creative Commons Attribution 4.0 International License (http://creativecommons.org/licenses/by/4.0/), which permits use, sharing, adaptation, distribution and reproduction in any medium or format, as long as you give appropriate credit to the original author(s) and the source, provide a link to the Creative Commons license and indicate if changes were made.

The images or other third party material in this chapter are included in the chapter's Creative Commons license, unless indicated otherwise in a credit line to the material. If material is not included in the chapter's Creative Commons license and your intended use is not permitted by statutory regulation or exceeds the permitted use, you will need to obtain permission directly from the copyright holder.

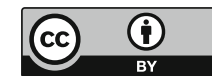

